\title{
Hilario Ramírez Morales y la OEEM. Resistencia cultural mixteca en Ayutla de los Libres, Guerrero
}

\author{
Hilario Ramírez Morales and the OEEM. Mixteca Cultural Resistance in \\ Ayutla de los Libres, Guerrero
}

Hilario Ramírez Morales e a OEEM. Resistencia cultural mixteca en Ayutla de los Libres, Guerrero

\author{
José Carmen Tapia Gómez \\ Universidad Autónoma de Guerrero, México \\ jtapia6@yahoo.com.mx \\ https://orcid.org/0000-0002-9313-1792 \\ Rosalba Díaz Vázquez \\ Universidad Autónoma de Guerrero, México \\ rosaldiaz@yahoo.com.mx \\ https://orcid.org/0000-0001-5304-1840
}

\section{Resumen}

Este documento se centra en la lucha social emprendida por el líder del te savi (mixteco) Hilario Ramírez Morales, la cual comenzó a mediados de los años 60 en el municipio de Ayutla de los Libres, estado de Guerrero, y que le llevó a ser asesinado en 1981. El objetivo principal de esta investigación se inscribe en el paradigma hermenéutico-reflexivo. Con este tipo de análisis, se inicia un acercamiento a la vida de este personaje histórico a fin de dar a conocer la lucha que realizó, revestida y caracterizada de resistencia cultural. Los procedimientos llevaron a registrar principalmente información documental, complementada en menor medida con testimonios orales, que resumen las tareas que coordinó el dirigente mixteco para promover, junto con otros jóvenes de su etnia, acciones liberadoras pacíficas encaminadas, primero, a establecer redes intercomunitarias y asociaciones civiles mediante 


\section{Revista Iberoamericana \\ de las Ciencias Sociales y \\ Humanísticas}

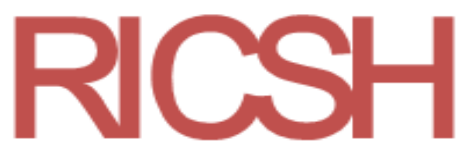

ISSN: 2395 - 7972

la constitución de la Organización de Estudiantes y Ex-Estudiantes Mixtecos (OEEM); y segundo, en la construcción consensuada en las localidades originarias de un "programa de lucha" que retomaba las demandas más sentidas de la población. Entre los resultados destaca que Hilario Ramírez fortaleció alianzas con un grupo de catequistas católicos liberales y, con ellos, robusteció la estructura organizacional a nivel municipal que hasta el día de hoy perdura. Asimismo, Ramírez logró impulsar congresos étnicos en La Concordia, Coapinola, Ahuacachahue, ciudad de Ayutla y otras localidades. Su lucha, a la postre, contribuyó a que la OEEM lograra la introducción del sistema de educación bilingüe, conquista legítima para las comunidades que no querían perder su lengua, y que reclamaban a la vez el uso del idioma castellano para defender sus derechos sojuzgados por la clase mestiza opresora en la región mixteca. Sin embargo, en 1981, la embestida reaccionaria de cacicazgos locales de la otrora estirpe indígena se recrudeció. Frente a las denuncias de la OEEM, aquellos grupos adinerados optaron por ultimar al líder el 21 de mayo. Con esa acción criminal los caciques creyeron acabar la lucha y resistencia de Hilario Ramírez.

Palabras clave: discriminación, explotación, grupos caciquiles, intercambio desigual, región mixteca, resistencia cultural.

\section{Abstract}

This document focuses on the social struggle waged by the te savi (Mixtec) leader Hilario Ramírez Morales, which began in the mid-1960s in the municipality of Ayutla de los Libres, Guerrero state, and was cut short with his death in 1981. The main objective of this research is inscribed in the hermeneutic-reflexive paradigm. With this type of analysis, an approach to the life of our historical person begins in order to publicize the struggle he carried out, covered and characterized by cultural resistance. The procedures led to the recording mainly of documentary information, complemented to a lesser extent by oral testimonies, which summarize the tasks that the Mixtec leader coordinated to promote, together with other young people of his ethnic group, peaceful liberating actions aimed, first, at establishing intercommunity networks and civil associations through the constitution of the Organización de Estudiantes y Ex-Estudiantes Mixtecos (OEEM); and second, in the consensual construction in the original localities of a "struggle program" that took up the most heartfelt demands of the population. Among the results, it stands out that Hilario Ramírez strengthened alliances 


\section{Revista Iberoamericana \\ de las Ciencias Sociales y \\ Humanísticas}

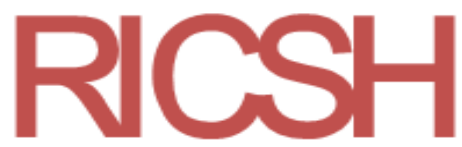

ISSN: 2395 - 7972

with a group of liberal Catholic catechists and, with them, strengthened the organizational structure at the municipal level that continues to this day. Likewise, Ramírez managed to promote ethnic congresses in La Concordia, Coapinola, Ahuacachahue, the city of Ayutla and other locations. Their struggle, in the end, contributed to the OEEM achieving the introduction of the bilingual education system, a legitimate conquest for the communities that did not want to lose their language, and that at the same time demanded the use of the Castilian language to defend their rights under the control of the oppressive mestizo class in the Mixtec region. However, in 1981, the reactionary onslaught of local chiefdoms of the former indigenous line intensified. Faced with complaints from the OEEM, those wealthy groups chose to kill the leader on May 21. With this criminal action, the caciques believed that the struggle and resistance of Hilario Ramírez ended.

Keywords: discrimination, exploitation, unequal exchange, Mixtec region, cultural resistance.

\section{Resumo}

Este documento enfoca a luta social empreendida pelo líder do te savi (Mixtec) Hilario Ramírez Morales, que teve início em meados da década de 1960 no município de Ayutla de los Libres, estado de Guerrero, e que o levou ao assassinato em 1981 O objetivo principal desta pesquisa insere-se no paradigma hermenêutico-reflexivo. Com este tipo de análise, inicia-se uma abordagem sobre a vida desta figura histórica no sentido de dar a conhecer a luta que travou, percorrida e caracterizada pela resistência cultural. Os procedimentos conduziram ao registo principalmente de informação documental, complementada em menor medida por testemunhos orais, que sintetizam as tarefas que o dirigente mixteca coordenou para promover, em conjunto com outros jovens da sua etnia, acções pacíficas de libertação visando, em primeiro lugar, a estabelecimento de redes e associações intercomunitárias civil, através da constituição da Organização de Estudantes e Ex-Estudantes Mixtec (OEEM); e, segundo, na construção consensual nas localidades originárias de um "programa de luta" que atendesse às demandas mais sinceras da população. Entre os resultados, destaca-se que Hilario Ramírez fortaleceu alianças com um grupo de catequistas catecistas liberais e, com eles, fortaleceu a estrutura organizacional em nível municipal que continua até hoje. Da mesma forma, Ramírez conseguiu promover congressos étnicos em La Concordia, 


\section{Revista Iberoamericana \\ de las Ciencias Sociales y \\ Humanísticas}

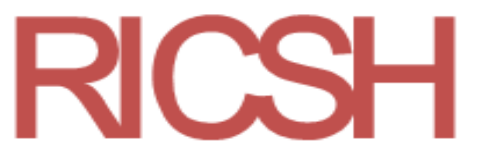

ISSN: 2395 - 7972

Coapinola, Ahuacachahue, na cidade de Ayutla e em outras localidades. A sua luta, no final, contribuiu para que a OEEM conseguisse a introdução do sistema de ensino bilingue, uma conquista legítima para as comunidades que não queriam perder a sua língua e que ao mesmo tempo exigiam o uso da língua castelhana para se defender. seus direitos sob o controle da classe mestiça opressora da região Mixteca. No entanto, em 1981, o ataque reacionário de chefias locais da antiga linha indígena se intensificou. Diante das reclamações da OEEM, esses grupos ricos optaram por matar o líder em 21 de maio. Com essa ação criminosa, os caciques acreditaram que a luta e a resistência de Hilario Ramírez acabaram.

Palavras-chave: discriminação, exploração, grupos caciquile, troca desigual, região Mixtec, resistência cultural.

Fecha Recepción: Agosto 2019

Fecha Aceptación: Diciembre 2020

\section{Introducción}

El municipio de Ayutla de los Libres se localiza en la Costa Chica, al sureste del actual estado de Guerrero, en una de sus siete regiones naturales, con una superficie local de $7.35 \mathrm{~km}^{2}$ (Raúl Luna, 2004, p. 3), y tiene como cabecera a la ciudad de Ayutla. El territorio fue desde 1522 escenario de violentas defensas territoriales por parte de sus habitantes frente al Imperio azteca, la Corona española y la tiranía de López de Santa Ana, entre otras, sin perder de vista las amenazas contemporáneas, cuyos poderíos no pudieron y no han podido destruir a las comunidades originarias allí radicadas, ya que, como ha dicho Silvia Soriano (1994), “permanecen, se auto-reproducen y continúan” (pp. 71-72).

En tal contexto histórico, la vida del estudiante universitario y líder de na savi ('la gente de la lluvia’ o mixteca), Hilario Ramírez Morales, significó la inconformidad social cotidiana de su Ñuu Savi ('pueblo de la lluvia'), expresada en resistencia cultural y lucha étnica de las comunidades en defensa de sus recursos naturales y su propia identidad. Esto tomó fuerza desde 1965, cuando, junto con Benito Narciso Morales, Filemón Francisco Santos, Agustín Morales y otros compañeros, deciden organizarse y fundan, luego de 12 años de gestación, en diciembre de 1977 (Narciso, 2002, p. 43), la Organización de Estudiantes y Ex-Estudiantes Mixtecos (OEEM) del municipio de Ayutla de los Libres, hasta que es ultimado por indicaciones de gente adinerada — asentada en Coapinola, Rancho Ocoapa y 


\section{Revista Iberoamericana \\ de las Ciencias Sociales y \\ Humanísticas}

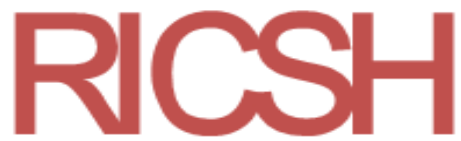

ISSN: 2395 - 7972

La Concordia_, en plena región mixteca, en el año de 1982 (Filemón Francisco Santos, mayo de 2016, entrevista).

En la vida de Hilario Ramírez Morales se contrastan múltiples acontecimientos interrelacionados que lo impactan personal y socialmente. Ya desde 1971 la entidad guerrerense estaba muy convulsionada por la presencia de fuertes movimientos insurgentes bajo el liderazgo de los profesores y comandantes guerrilleros Genaro Vázquez Rojas y Lucio Cabañas Barrientos, que exigían justicia para los mexicanos. En este marco, en mayo de 1972, en la Universidad Autónoma de Guerrero (UAGro) asume como nuevo rector el doctor Rosalío Wences Reza, quien enarbola el proyecto popular educativo denominado Universidad-Pueblo, con el que abre las puertas de la institución a la sociedad guerrerense, y da cobijo a hijos de obreros, campesinos, artesanos y clases subalternas de origen humilde. Entonces, se fundan varias "preparatorias populares" en las regiones del estado, comedores universitarios, casas del estudiante, dispensarios médicos y, algo muy importante, se extienden becas económicas y condonaciones de pago sobre inscripción escolar del 50 y $100 \%$, que benefician a estudiantes indígenas pobres al ingresar a la máxima casa de estudios.

En la ciudad de Chilpancingo existía la Auténtica Casa del Estudiante Guerrerense (ACEG), que hasta septiembre de 1971 estuvo ubicada en Mariano Abasolo número 30 y luego trasladada a la calle 16 de septiembre número 18 (Tapia, 2015) ${ }^{1}$, albergue que hospedó a jóvenes alumnos de muy escasos recursos económicos, estudiantes de secundaria, preparatoria y carreras profesionales de nivel superior. En 1972, el movimiento estudiantil democrático y reivindicativo resurge en la UAGro, en gran medida alentado por el liderazgo de la ACEG y la presencia en su seno de jóvenes como Juan García Costilla, Octaviano Santiago Dionisio y Abelardo Alarcón Orduña, entre otros. En este período se funda la primera etapa de la organización política universitaria denominada Unión Estudiantil Guerrerense (UEG), donde confluyen infinidad de muchachos encabezados por Guillermo Sánchez Nava, Víctor Hugo Herrera Pegueros y Ernesto Alarcón Orduña, que se identifican con las luchas sociales de sectores marginados de Guerrero.

\footnotetext{
${ }^{1}$ José Carmen Tapia Gómez, coautor de este ensayo, fue morador de la ACEG de agosto de 1970 a julio de 1980 .
} 


\section{Revista Iberoamericana \\ de las Ciencias Sociales y \\ Humanísticas}

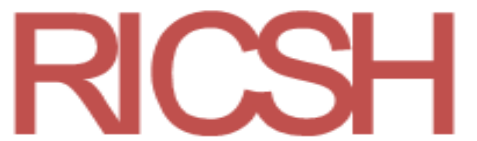

ISSN: 2395 - 7972

Bajo este ambiente, con dificultades de lenguaje en un campo de "mestizos", llegó a Chilpancingo el joven mixteco Hilario Ramírez Morales. Proveniente de la comunidad de El Piñal — en la zona montañosa del municipio ayutleco-, no escatimó esfuerzos en promover su identidad cultural: señaló abiertamente que las localidades mixtecas que componían su municipio padecían pobreza extrema, falta de escuelas bilingües e infinidad de problemáticas milenarias que se debían resolver, como era la venta a buen precio de su pequeño comercio de origen agrario. En este contexto, en septiembre de 1973, Hilario se inscribe como alumno de la Preparatoria Popular Ernesto Che Guevara, dependiente de UAG, e ingresa como morador disciplinado de la ACEG, donde destaca por su insistencia en dar a conocer su identidad étnica y por encontrar solidaridad para su causa, siempre con su dicho: "Soy mixteco de Ayutla de los Libres" (Tapia, 2015).

Entre 1976-77, casi al concluir sus estudios de preparatoria, Hilario Ramírez Morales se vuelve asiduo activista estudiantil, junto con Gumersindo Parra Barrera, Francisco Santiago Dionisio, Gustavo Ávila Serrano y Ofelio Martínez Yanes, quienes lo hacen actuar en equipo mediante círculos de estudio. Asimismo, se incorpora al proyecto de reestructuración de la Federación Estudiantil Universitaria Guerrerense (FEUG), dirigida por la ACEG y el Dormitorio Universitario. En esas lides, en un recorrido por la región de Tierra Caliente en compañía de un profesor, el auto Volkswagen en que viajaban por la noche derrapó - o el conductor se durmió-: el vehículo terminó volcado en la carretera. El accidente en mención tuvo como consecuencias para Ramírez Morales contusiones en el cuerpo y daño en su rostro, con la destrucción de su dentadura frontal, hecho que contribuyó para que se ganara el mote del Abuelo, con el que será conocido entre muchos universitarios hasta su muerte.

Hilario Ramírez Morales tuvo siempre entre sus objetivos la reivindicación de los derechos de su pueblo mixteco. Por esto, buscó mejorar su discurso para darse a entender. Guillermo Sánchez y otros compañeros de la ACEG fueron sus asesores en oratoria popular. Ello le permitió fluidez en sus mensajes políticos. Así, desde 1975, en compañía de su paisano Agustín Morales Hernández, también mixteco estudiante preparatoriano, y de los profesores na savi Filemón Francisco Santos, Benito Narciso Morales y Leonardo Santiago, se abocó a la creación de la OEEM, con el propósito de hacer frente a los caciques y acaparadores que se robaban los recursos naturales (madera) del área comunitaria (Narciso, 2002), ya que estos personajes siniestros lucraban además con los bajos precios de sus 


\section{Revista Iberoamericana \\ de las Ciencias Sociales y \\ Humanísticas}

ISSN: $2395-7972$

productos agropecuarios (aguacate criollo, mamey, guanábana, piña, panela, animales domésticos) y explotaban la fuerza de trabajo barata de las comunidades originarias mixtecas.

En ese trance, el grupo estudiantil mixteco liderado por el Abuelo recibe amplio apoyo de la ACEG y de los núcleos democráticos que dirige la FEUG, hasta que la organización social indígena (OEEM) logra su primer congreso, realizado en la comunidad de La Concordia los días 26, 27 y 28 de junio de 1977. Este evento registra la participación de 29 comunidades étnicas, cuyo objetivo principal fue: 1) combatir el analfabetismo imperante en la zona mixteca del municipio, 2) poner alto los abusos realizados por los comerciantes que quitaban los productos agropecuarios a los mixtecos en los caminos y 3 ) suprimir los medidas alcabalatorias que el Ayuntamiento de Ayutla imponía por el traslado de mercancías de origen indígena y por su venta en los mercados dominicales. Un tema adicional es la denuncia contra acaparadores e intermediarios que, confabulados con los funcionarios locales, compraban los productos a pie de comunidad o en los caminos y brechas a bajísimos precios, donde cualquier negativa de los campesinos les impedía seguir su trayecto hacia la ciudad cabecera. Las otras demandas de la población eran la construcción de nuevas terracerías e instalación de una zona escolar bilingüe (García Costilla, 20 de enero de 2011).

En los siguientes congresos de la OEEM, prosiguen otras demandas hacia los entes gubernamentales, los cuales hacen caso omiso a escucharlas y cumplirlas. Pero la na savi siente que se vive una etapa de transición. Por ello, en los eventos sucesivos (congresos, asambleas), se acuerda establecer relaciones interétnicas con otros pueblos hermanos, para pelear los derechos comunes, "pues se aprecia un ligero cambio en la mentalidad, particularmente en los jóvenes" (Narciso, 2002, p. 29).

\section{Referencial teórico-metodológico}

Benito Narciso (2002), compañero de lucha de Hilario Ramírez Morales, divulgó que las comunidades que eran parte de su propia etnia por mucho tiempo solo fueron visitadas durante campañas electorales por el partido de Estado gobernante. Pasados esos procesos, el mixteco "deviene en el ser más alejado e ignorado" (p. 21). Entonces, las problemáticas relacionadas con la miseria, abandono social y resistencia cultural del Ñuu Savi de Ayutla para sobrevivir fueron aspectos bastante desconocidos al exterior de sus comunidades hasta finalizar los años 70 (Tapia, 2018, pp. 136-152). Es decir, dicha resistencia cultural mixteca 


\section{Revista Iberoamericana \\ de las Ciencias Sociales y \\ Humanísticas}

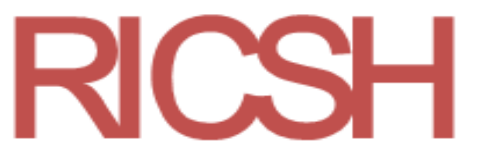

ISSN: $2395-7972$

viene de lejos, pues sus "áreas de refugio indígena" formaron parte de dicha estrategia milenaria.

Con diversos datos recabados en las regiones mixtecas de Guerrero, los autores de este ensayo han logrado consolidar una base de datos que refiere a la historia de la resistencia ocurrida en la legendaria Ayotlán (Ayutla) y áreas de la vieja Acatlán, en San Luis. Fue mediante revisiones bibliográficas, de archivos parroquiales y reconstrucción de la memoria histórica que se pudo recuperar y sistematizar parte del pasado local de na savi. Así se logró conocer que la zona mixteca de Ayutla estuvo sujeta a un dilatado proceso de despojo tributario, perpetrado, primero, por la Triple Alianza prehispánica encabezada por MéxicoTenochtitlan (Rafael Rubí, 1993), información que ratifica Raúl Vélez Calvo (1998, p. 242), quien afirma que en 1487 casi todas las zonas mixtecas del actual estado de Guerrero cayeron bajo el poder del Imperio azteca; y, segundo, se pudo comprender asimismo, con otros datos históricos, cómo el área mixteca de la Costa Chica de la entidad estaba inscrita en la vertiente de penetración del capitalismo salvaje en su hábitat regional, desde la etapa colonial hasta nuestros tiempos.

Danielle Dehouve (2001) asevera que, en su lucha de resistencia, los mixtecos de Ayutla se expandieron por el este, dejando parte de la costa del Sur a "expensas de los tlapanecos" o me' phaa (p. 42), con quienes eran aliados. La extracción de tributos en productos y trabajo diezmó a la población costera e hizo estragos en Ayutla, que se rebela contra el sistema colonial (Dehouve, 2001, pp. 101-102).

Rolf Widmer (1990, pp. 77-79 y 116) relata a su vez que la Costa Chica de Guerrero fue asaltada y conquistada militarmente entre 1521 y 1522 por españoles bajo órdenes de Pedro de Alvarado (Tonatiuh), donde sus habitantes presentaron inicialmente una débil resistencia indígena, pero que explotó entre los yopes o yopis, tlapanecos y mixtecos de Acaxitla, quienes nunca quisieron obedecer ni servir a Moctezuma en la etapa previa (Vidal, 1987, p. 32). Por ello, sin mayores dificultades por la vía militar, los conquistadores invaden sus tierras y los persiguen por el monte, y la Corona española distribuye sus derechos étnicos a encomenderos como Pedro Lozano.

En el caso de la región mixteca y tlapaneca de Acatlán y Ayotlán (Ayutla), lo ocurrido después de la invasión hispánica da paso a la etapa de mayores inconformidades socioculturales. Por un lado, contra el conquistador Diego Pardo, un andaluz de Moguer que había actuado en Cuba y en Las Higueras, quien funda y obtiene en encomienda la Villa de 


\section{Revista Iberoamericana \\ de las Ciencias Sociales y \\ Humanísticas}

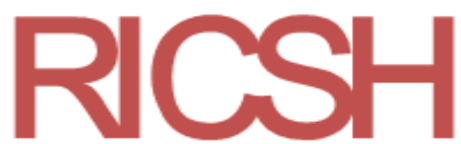

ISSN: 2395 - 7972

San Luis (Acatlán). Por otro, contra el déspota encomendero Pedro Lozano, que fue instalado en Ayutla. Ambos impusieron "excesivos gravámenes tributarios" a los indios como era la tónica de estos personajes en toda América Latina (Gunder, 1967, p. 91). Esta situación se agudiza entre 1523 y 1530 y culmina con el levantamiento de los aguerridos y belicosos yopes o yopis en 1531 en las dos zonas costeras, lo que obliga al grueso de peninsulares huir de San Luis y retirarse de Ayutla por temor a los rebeldes; queda solo Pardo, junto al cura y un regidor, resguardados por sus "guardias blancas". Lozano y su familia se asentaron en Chilapa, aunque administra la encomienda de Ayutla a través de caciques de la zona, quienes servían como intermediarios. No obstante, la conspiración yope o yopi fue ahogada en sangre y los sobrevivientes perseguidos hasta las estribaciones de la montaña y sierra costeña (Vidal, 1987, p. 33).

Con base en estas apreciaciones, se hace necesario agregar que Pedro Lozano fue un invasor de origen español que entre 1523-1524 obtuvo permiso de Hernán Cortés — por intervención de Alvarado- para hacerse de la encomienda de la vieja Ayotlán; a la vez, adquirió casas en la zona de Chilapa y sitios de estancias ganaderas cerca de Jicayán de Pedro Nieto y Tututepec (Widmer, 1990, p. 127), en territorios de lo que hoy es Oaxaca. Obteniendo el permiso real, este encomendero emprende a lo largo de varios años la extracción de riqueza mineral (oro), maderable (pino-encino) y textil lugareña (ropa tejida). Este largo proceso de expropiación y separación de los medios y condiciones de vida del labrador —indígena y campesino - en la zona mixteca de Ayutla por el capitalismo salvaje ha significado a la vez la existencia de formas originales de resistencia a través de las cuales las comunidades han sustentado sus relaciones vitales sustentables, enfrentadas a estructuras socioculturales occidentales adversas; medios comunitarios que se pronuncian como un proyecto "diferente" y profundo. Estas relaciones expresan la pervivencia de una "matriz civilizatoria" originaria cuya fuente fue parcialmente truncada, pero donde su venero y manantial verdadero siguieron - y siguen fluyendo- para alimentar y reconstruir su proyecto autonómico en los nuevos tiempos.

No puede ocultarse, asimismo, como lo refiere Rafael Rubí (1993), que los excedentes sociales o comunitarios arrancados paulatinamente de las manos indígenas y su territorio en forma de tributos beneficiaron particularmente a la Corona, encomenderos, Iglesia y nobleza indígena, y ello ocurre desde que ingresa y se instaura la encomienda regional, sea en servicio gratuito de mano de obra, en bienes-producto (oro en polvo, mantas, 


\section{Revista Iberoamericana \\ de las Ciencias Sociales y \\ Humanísticas}

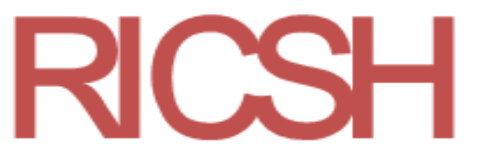

ISSN: 2395 - 7972

cacao), servicio en trabajo forzoso y en la obligación de aportar nuevos tributos valuados en pesos oro, aspectos que vienen a constituirse en capital originario en manos de los encomenderos, esto es, en trabajo y materias primas no pagados a los productores directos de origen nativo.

De acuerdo con datos recientes rescatados de la memoria histórica por sabios mixtecos de Ayutla, la población emigró a los espacios de refugio - integrada por el grueso de las comunidades de dicha etnia en Ayutla_, ubicados en Coapinola, Ahuacachahue y Rancho Ocoapa (Tapia, 2018, p. 140-147). Según fuentes orales, los principales (ancianos) atribuyen que sus comunidades han resistido desde el proceso de invasión y ulterior colonización al lograr emigrar hacia las montañas, donde fueron menos golpeados culturalmente por el encomendero, no así aquel segmento ubicado en la parte costera.

Posteriormente, frente a la inconformidad, el general Morelos enciende el descontento en Tlapa, Metlatónoc y la costa del Pacífico en 1811, con el fuego social del movimiento de independencia que alcanza a la costa de la mar del Sur por San Luis y Ayutla. Francisco López Bárcenas (2015) afirma que, en la Costa Chica de Oaxaca y Guerrero, los mixtecos despojados vieron en la guerra de independencia la oportunidad de "vengar los agravios sufridos por los españoles” y se levantaron en su gran mayoría (pp. 31-34).

Sin embargo, no fue suficiente, pues aunque el texto Sentimientos de la Nación, promulgado en Chilpancingo en 1813 por el generalísimo José María Morelos (Fernández, 2013, pp. 114-118), declara abolida la esclavitud y reivindica los derechos de los pueblos originarios, la na savi de Ayotlán siguió esclavizada por la usura y sus pobladores vivieron despojados de sus tierras y territorio. Así se puede entender que, años después, los mixtecos de Ayutla incorporaran sus formas de resistencia cultural en la lucha final por la independencia de México frente a los españoles, al lado del general insurgente don Vicente Guerrero.

Por ello, en 1854, por seguir al viejo insurgente Juan Álvarez, algunos de sus peones se incorporaron a la lucha que proclama el Plan de Ayutla, comandada en la zona ayutleca por Florencio Villarreal, militar confabulado en la muerte del general Guerrero. Aunque muchos mixtecos participaron en los ejércitos que combatieron de manera frontal para derrocar al dictador Antonio López de Santa Ana, sus localidades étnicas siguieron y continúan en la pobreza extrema, a pesar incluso de la ola revolucionaria zapatista de 19111919. 


\section{Revista Iberoamericana \\ de las Ciencias Sociales y \\ Humanísticas}

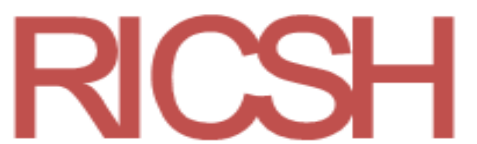

ISSN: $2395-7972$

\section{Resultados alcanzados en el estudio}

Al iniciar la investigación cualitativa que permite presentar este ensayo, se orientaron propósitos básicos de indagación en forma de preguntas e hipótesis de trabajo para conocer de los años 70 aspectos centrales como: 1) cuál era la situación sociocultural de na savi del municipio de Ayutla frente a los alcances de la revolución mexicana; 2) razones o causas que hacían que sus comunidades originarias siguieran en alta marginación y aguda miseria económica; 3) incluso, a decir de Benito Narciso (1989, entrevista), el por qué en 1970 los mixtecos lugareños parecían no existir en el mapa municipal, pues "ni siquiera se les consultaba en las elecciones locales y federales", ya que las decisiones las tomaban los líderes del partido en el poder, sin hacer consulta a la población, y 4) las raíces socioculturales que influyeron en la lucha social de los jóvenes, particularmente en Hilario Ramírez Morales.

Los resultados de la investigación permitieron corroborar que la OEEM "fue una organización de estudiantes y profesores que se constituyó como una asociación civil de origen indígena, ante la falta de liderazgos y gestores que pudieran recuperar las demandas de los habitantes de la zona de na savi” (García Costilla, 20 de enero 2011).

La lucha étnica emprendida por Hilario Ramírez nació, en los hechos, a principios de los años 70, al formarse en la UAGro círculos de estudio y reflexionar sobre la problemática que vivían entonces los indios de Guerrero; no obstante, esa lucha cultural de resistencia tuvo como eje la acción social del movimiento étnico de los mixtecos con base en sus propias decisiones e inspiración sociohistórica.

Los círculos de estudio se identificaron con Hilario Ramírez Morales, quien se incorpora a este proyecto convirtiéndose al poco tiempo en su coordinador y, en 1976, en el principal dirigente de dicha forma de organización y auto-reflexión. Así, como ya se mencionó, este líder logró organizar y conducir su primer congreso regional en la comunidad de La Concordia los días 26, 27 y 28 de junio de 1977, evento donde se constituyó formalmente la OEEM el día 28 del mismo mes y año (García Costilla, 20 de enero de 2011). Desde entonces, los sucesivos congresos mixtecos siguieron programándose por varios años, los cuales eran conducidos por Hilario Ramírez siguiendo el mismo rumbo programático hasta su muerte.

La representación de 29 comunidades mixtecas asistentes al primer congreso de la OEEM fortalecieron su estructura por la importancia de sus demandas: 1) maestros bilingües para las comunidades; 2) solución a los elevados índices de analfabetismo; 3 ) rechazo a los 


\section{Revista Iberoamericana \\ de las Ciencias Sociales y \\ Humanísticas}

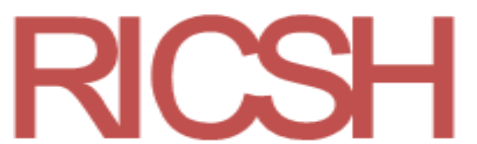

ISSN: $2395-7972$

impuestos establecidos de facto por los acaparadores y el Ayuntamiento a los campesinos que transitaban con mercancía por los caminos y brechas a la cabecera municipal; 4) derogación de los impuestos instituidos por la venta de productos en el mercado municipal; 5) gestión de apertura de nuevas brechas que comunicaran con Ayutla, y 6) demanda de creación de una zona escolar bilingüe.

Según los relatos de Juan García Costilla, la lucha contra los impuestos en los caminos y la respuesta dada a este problema por el Ayuntamiento de Ayutla potenció y fortaleció la estructura social y política de la OEEM.

De acuerdo con indagaciones realizadas sobre este tema (Tapia, 2018), una de las primeras acciones que emprende Hilario Ramírez con el apoyo de su organización fue la gestión y formación de brigadas de alfabetización del programa de educación popular de la UAGro, donde destaca la presencia del profesor Arquímedes García Castro, en el marco del proyecto Universidad-Pueblo.

Con este estudio se logra conocer que el apoyo dado a las comunidades por la UAGro tuvo éxito por la formación y capacitación de alfabetizadores de la región, dirigido a los secretarios de las comisarías y a egresados de nivel secundaria; la Universidad solo donó a las comunidades indígenas butacas, pizarrones, lámparas de gasolina, entre otros implementos para los círculos de estudio (García Costilla, 21 de enero de 2011), con el afán de resolver problemas de analfabetismo alarmante hasta en un noventa por ciento en la mayoría de la población.

Los dirigentes universitarios de alta sensibilidad social, Guillermo Sánchez Nava, Saúl López Sollano y Juan García Costilla, desde la UAGro apoyaron las iniciativas del coordinador Hilario Ramírez y del profesor Benito Narciso Morales, subcoordinador de la OEEM, quienes se propusieron dar respuesta a los reclamos de las comunidades en los congresos mixtecos; ambos encabezaron la lucha por dotar a las localidades con profesores bilingües, que a la postre les permitiera conocer la naturaleza del mundo mestizo y reproducir su propia cultura. Esta es la raíz de la resistencia ética de na savi en el aspecto de la matriz cultural que reivindican.

Respecto a los resultados que arroja esa lucha nodal de Hilario Ramírez, referente a impedir que continuaran los impuestos en las carreteras y caminos, García Costilla (21 de enero 2011: párrafo 10) menciona: 


\section{Revista Iberoamericana \\ de las Ciencias Sociales y \\ Humanísticas}

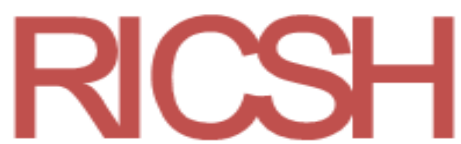

ISSN: 2395 - 7972

La dirección de la OEEM se planteó buscar solución a esta demanda de las comunidades indígenas; la oportunidad se presentó en enero de 1978, en la toma de posesión del señor Leonardo Vázquez como presidente municipal, donde rompiendo el protocolo se presenta en la tribuna el pliego de demandas de las comunidades, que el edil no quiso recibir. Esta fue de las primeras acciones trascendentales de la organización, y a partir de ese momento se suprimieron los impuestos de los caminos, dejando solamente los impuestos que se cobraban en el mercado.

Lo anterior remite a conocer las reivindicaciones propuestas, lo cual resulta evidente en las anotaciones realizadas por García Costilla (21 de enero de 201: párrafo 11), quien indica que:

A partir de ese momento se [intensificaron] las visitas de la organización a las comunidades, donde se vivía un ambiente de hostigamiento por los caciques [hacia] los líderes indígenas, que se sorprendían con los alcances de la nueva organización, y se filtraba la información de que serían eliminados los dirigentes comunitarios y los comisarios simpatizantes de la OEEM.

De todo lo anterior se observa en la hipótesis central que los enemigos a vencer fueron los caciques lugareños apoderados de las comisarías de bienes comunales. Por supuesto, Pedro Luisa negó los hechos y argumentó que él siempre tuvo interés en dejar la Comisaría de Bienes Comunales de Coapinola. En su entrevista sostiene que nada tuvo que ver en la muerte de Hilario Ramírez Morales, cuyo crimen aún le achacan. Agregó que depositó en el banco recursos financieros que llegaron a los 50000 pesos, provenientes de un anticipo que les dio un empresario maderero de El Ocotito, quien bajaba la madera para su aserradero. Pero añadió que ese dinero era para arreglar la carretera hacia las comunidades mixtecas; que había prestado a la comisaría local la cantidad de 15000 pesos para las fiestas de la Virgen, aunque ese dinero regresaría al banco. No obstante, la lucha comunitaria lo hizo abandonar el cargo. 


\section{Revista Iberoamericana \\ de las Ciencias Sociales y \\ Humanísticas}

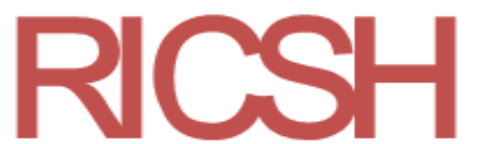

ISSN: $2395-7972$

\section{Asesinato del líder mixteco}

En 1978, Hilario Ramírez Morales estaba inscrito como alumno regular de la Facultad de Medicina de la UAGro. Sin embargo, su situación se vuelve azarosa, pues caciques adinerados de Coapinola, Rancho Ocoapa y La Concordia, encabezados por Pedro Luisa y don Juan Álvarez, ordenaron su asesinato. Para lograrlo, pagaron a un sicario, quien lo asedia en El Piñal y lo espera en los caminos de Rancho Ocoapa para “cazarlo”. Él, por su parte, teme ser diezmado como venado desde algún risco de los cerros, o ultimado por la espalda, como acostumbran hacerlo los pistoleros a sueldo en aquellos lugares. Sin embargo se escabulle y actúa clandestinamente. Alguien de sus compañeros, por propia necesidad, le obsequió una pistola .38 Súper con cinco tiros. Empero, el líder temía seriamente por su vida, pues era evidente que los matones de su tierra eran sicarios que no tenían límites cuando se disponían a fraguar y realizar un asesinato; de ahí que dijo a un camarada suyo que le cambiaba la pistola escuadra que portaba, por una tres ochenta con treinta cartuchos. El trato se hizo. Entonces $e$ l Abuelo regresa a su pueblo, rondando caminos, dispuesto a enfrentar su destino. El cansancio y las marchas forzadas por veredas y cerros merman su fortaleza, que aun en su calidad de joven de 25 años hacen escarnio. Lo vence el sueño y el cazador cruel lo encuentra dormido una mañana en su casa, junto al pie de un frondoso árbol, el 21 de mayo de 1981. Allí, sin miramiento, lo acribilla con una escopeta del 12, mientras el líder indígena se queda soñando para siempre.

Hilario Morales Ramírez muere asesinado en Rancho Ocoapa, al fungir como coordinador de la OEEM; su delito fue denunciar que los caciques de Coapinola y La Concordia medraban con los recursos provenientes de hipotecar los bosques maderables de la zona mixteca, y por exigir que los intermediarios no se quedaran con el valor del trabajo indígena. Fue víctima del contubernio de quienes se confabularon con los explotadores de los bosques desde el organismo descentralizado paraestatal Forestal Vicente Guerrero, y vieron en Hilario un rival que se oponía a los rapamontes. Existía ya una amenaza de muerte

de los hermanos Pedro Luisa y Juan Álvarez, quienes eran los caciques y acaparadores de Coapinola; Pedro fue por más de 15 años el comisariado agrario, y Juan el secretario de la comunidad y comisario mayor (Benito Narciso Morales, 1989, entrevista).

Sostiene García Costilla (21 de enero de 2011: párrafo 15): 


\section{Revista Iberoamericana \\ de las Ciencias Sociales y \\ Humanísticas}

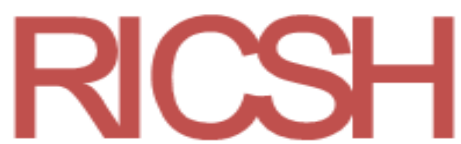

ISSN: $2395-7972$

Después del asesinato de Hilario Ramírez Morales se desata una cadena de crímenes de dirigentes indígenas que se mantenían en movimiento contra la tala inmoderada de los bosques, presumiéndose la responsabilidad del grupo de caciques que tenía su antecedente en 1970, año en que Juan Álvarez asume el poder comunal, secundado por Pedro Luisa, quien usurpó la comisaria de bienes comunales de 1982 a 1998 y se opuso a cederlo, apoyado por un grupo de bandoleros que tenían asolada la región e intimidados a los ancianos mixtecos.

En esa larga ola de crímenes secuenciales, en febrero de 2009 fueron ultimados Raúl Lucas y Manuel Ponce, continuadores de la lucha de Hilario Ramírez. Con detalles, relata este episodio Luís Hernández Navarro (24 de febrero de 2009) en su columna "Astillero" del diario nacional La Jornada, donde se expresa la impunidad de que gozaban grupos criminales lugareños.

\section{Discusión}

La ola de crímenes e intimidaciones llevó a que en 1978 los miembros de la OEEM extremaran precauciones en su andar por la zona mixteca. La mayoría suspendió las visitas a las comunidades; procuraban llegar con aviso anticipado solo entre compañeros; se arribaba a los pueblos de manera esporádica y se caminaba por las veredas en las noches. Sus principales dirigentes pasaron a la vida clandestina, como es el caso del profesor Benito Narciso Morales, situación que trae consigo la suspensión de la vida orgánica pública.

No obstante, Hilario Ramírez Morales se planteó de cierta forma asumir una actitud heroica. Alguna vez, cuando el rector Wences Reza solicitó ser protegido ante hombres armados al servicio de grupos fácticos que disputaban la rectoría universitaria, él se autopropuso participar en 1978 como parte de la brigada protectora, cuando solo portaba una pistola calibre .22 escuadra en mal estado. En otra ocasión, estuvo a punto de darle un tiro a un maestro de la Prepa 1 de la UAGro, porque aquel discrepaba de algunas tácticas de los jóvenes líderes. Mostraba, pues, este dirigente mixteco, arrojo y decisión para enfrentar a quienes creyó que eran sus adversarios, y mayor coraje contra los enemigos de su lucha social. 


\section{Revista Iberoamericana \\ de las Ciencias Sociales y \\ Humanísticas}

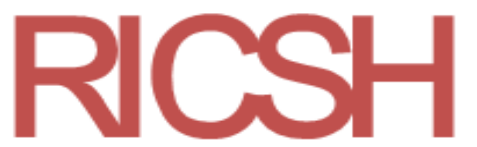

ISSN: 2395 - 7972

En contraparte, los dirigentes localizados en la zona mixteca de Ayutla optaron por tomar precauciones, e incluso decidieron no enfrentar de manera directa a sus detractores. Así lo señalan en entrevistas los líderes Benito Narciso (junio de 1999, entrevista) y Filemón Francisco Santos (mayo de 2016, entrevista), quienes agregan que "el compañero Hilario" no atendía las indicaciones que le proponía el grupo dirigente, pues se confiaba en que podía acudir a visitar a su familia y amigos venciendo los riesgos.

Se puede afirmar que el carácter recio de Hilario le impedía tener miedo a la muerte, pues llegó a decir a sus compañeros que estaba "dispuesto a batirse de frente con sus enemigos", siempre que no lo atacaran por la espalda. Sin embargo, lo venció el sueño y quedó desprotegido, a merced de los sicarios contratados por quienes estaban en contra de su cultura.

Posterior a la muerte de Hilario Ramírez, sus compañeros de lucha fundan la Organización de Pueblos Mixtecos-Tlapanecos (OPMT) Hilario Ramírez Morales del municipio de Ayutla, y retoman en su declaración de principios los fundamentos del movimiento emprendido por la OEEM. Este nuevo organismo social lo constituyeron un promedio de 22 comunidades de origen na savi y cinco de me' phaa (tlapanecas). En el carácter organizativo de la OPMT se advertía ya entonces (como necesidad) lo que actualmente el te savi Jaime García Leyva (2012) ha previsto: la exigencia de articular la resistencia con la continuidad histórica de la lucha social de los pueblos.

Este ensayo busca resaltar y visibilizar la lucha del líder mixteco Hilario Ramírez Morales en la distancia, aunque na savi no quiere hablar mucho del tema. No obstante, su historicidad merece ser tratada a mayor profundidad y acercamiento en su contexto social determinado, retomando las fuentes documentales y testimoniales vivas, revisando el impacto de su aporte a la luz de las nuevas formas de organización comunitaria, que tienen una continuidad, pues la zona mixteca sigue siendo una de las más pobres del estado. Esta área es también semillero de los movimientos de autodefensa comunitaria y escenario de una permanente lucha contra la paramilitarización y la inseguridad. Si bien los alcances de este artículo pueden ser limitados al tratar de describir su devenir y las acciones que emprendió el personaje analizado, sus aportes permiten reflexionar sobre temas de mayor alcance como los nuevos liderazgos indígenas y el papel de la universidad en su formación, o bien en su cooptación, así como la importancia de dar a conocer a las nuevas generaciones de ayutlenses 


\section{Revista Iberoamericana \\ de las Ciencias Sociales y \\ Humanísticas}

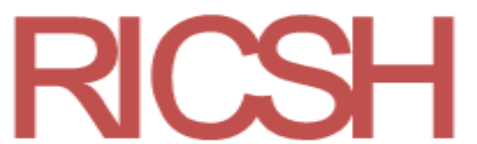

ISSN: 2395 - 7972

los personajes como Hilario Ramírez, que forma ahora parte de su historia y de la del estado de Guerrero.

Pero la principal fortaleza es que desde la perspectiva de la antropología social se puede hurgar en la memoria histórica y tradición oral de la "gente de la lluvia". Un hecho recuperable aún es el contacto que se tiene con viejos líderes y profesores bilingües, cuya experiencia en la lucha y conocimiento de las comunidades son vetas de investigación que pueden contribuir a enriquecer la historia del Ñu Savi. Sin embargo, hay debilidades que se relacionan con previsibles riesgos frente a sectores fácticos diversos que merodean por la zona mixteca y ponen en peligro tanto la vida de sus coterráneos como de los investigadores sociales. Por ello, conviene no perder de vista este factor que podría imposibilitar la investigación participante y el quehacer antropológico.

\section{Conclusiones}

El grupo dirigente de la OPMT consideró que era necesario que los niños mixtecos aprendieran y reprodujeran la vida social en su lengua madre y otros idiomas nacionales, ya que los profesores monolingües solo se encargaban de "castellanizar la enseñanza", y los chiquillos no pasaban de tercer año de primaria. En estos tiempos, este era el nivel máximo en la zona, y quienes deseaban concluir su educación primaria debían hacerlo en la cabecera municipal, Ayutla, lugar donde no existía zona escolar bilingüe. La primera escuela de este tipo fue fundada en Rancho Ocoapa, en plena área mixteca, en junio de 1983, dependiente de las jurisdicciones de Igualapa y Tierra Colorada, uno de los deseos que siempre planteó Hilario Ramírez.

El movimiento aumentó sus demandas: todas las comunidades querían escuelas bilingües. Pedían un mentor como un primer maestro que llegó a Rancho Ocoapa, quien trabajó en una choza de zacate. La gente supo que eso era posible desde 1981 a 1982, pues la OEEM había realizado "brigadeo" en toda la zona levantando censos de habitantes y niños en edad escolar, así como firmas de apoyo a la fundación de escuelas, con solicitudes que fueron enviadas al Instituto Nacional Indigenista, institución donde se pregonaba dar atención a los indígenas. Simultáneamente, varios jóvenes salieron a capacitarse en educación bilingüe para impartir esta educación: Agustín Morales Hernández, Filemón Francisco Santos y Leonardo Santiago, entre otros. 


\section{Revista Iberoamericana \\ de las Ciencias Sociales y \\ Humanísticas}

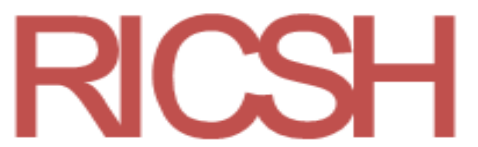

ISSN: 2395 - 7972

La lucha de resistencia étnica emprendida por Hilario Ramírez Morales y los miembros activos de la OEEM de Ayutla de los Libres, Guerrero, desde principios de los años 70, primero, y en la OPMT posteriormente, ha marcado los cimientos de una larga etapa de confrontación en contra de caciques locales adinerados y otros actores fácticos de oprobiosa presencia en el área mixteca de Ayutla.

Esa lucha social, a pesar de los descalabros y pérdidas humanas de parte de sus líderes, dejó como frutos nuevas formas de organización de na savi de aquella zona, que hoy se expresan como pervivencia histórica en defensa de sus derechos originarios.

Hilario Morales Ramírez dejó un legado imborrable entre sus congéneres mixtecos, que se traduce en que actualmente muchos jóvenes — hombres y mujeres — han emprendido la ruta de su autodefensa ante otros que no entienden la importancia de su cultura, pero también frente a criminales mercenarios, el mal gobierno mestizo y viejos intermediarios comerciales que cada día pierden presencia política. La gente del pueblo recuerda al líder en una escuela indígena de la comunidad de La Fátima que lleva su nombre, como lo recordó la Escuela Preparatoria Popular de Ayutla en alguna ocasión.

Los pueblos mixtecos y tlapanecos de Ayutla han conseguido otros niveles de organicidad y resistencia. Cuentan con cuerpos de autodefensa comunitarios y han logrado establecer un sistema de gobierno por usos y costumbres, cuyo ejemplo muestra la gran oportunidad que tienen las comunidades originarias de Guerrero para autogobernarse y generar nuevos sistemas de vida y trabajo.

Los conocimientos educativos de calidad y pertinencia social universitarios no pueden menos que brindar solidaridad y respeto a estos movimientos de resistencia.

Podemos concluir señalando que la indagación científica de la vida de na savi en Guerrero tiene una vertiente irrefutable en la metodología hermenéutica reflexiva, en documentos de primera mano, como son códices, archivos municipales y parroquiales, tesis de estudiosos del tema, manuscritos coloniales y del patrimonio arqueológico, que sirven a la investigación antropológica e histórica.

Analistas que resaltan la importancia de la investigación cualitativa con enfoques hermenéuticos aconsejan seguir procesos de reflexión, análisis y comparación que permitan entender los significados y comprender a los actores que se relatan en sus contextos directos (González, 2013, pp. 1-4). En esa vertiente, aparecen también Jairo Pérez Vargas, Johan Andrés Nieto y Juan Esteban Santa María (2019), quienes sostienen que "las propuestas 


\section{Revista Iberoamericana \\ de las Ciencias Sociales y \\ Humanísticas}

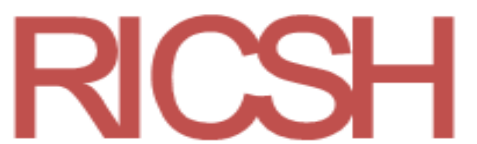

ISSN: $2395-7972$

emanadas de los textos" dependen de la "comprensión intersubjetiva", o sea la apropiación de la realidad contextual por el estudioso, que es el campo de vivencia de los sujetos que investiga (pp. 21-27).

A partir de dichas proposiciones, el enfoque histórico hermenéutico reflexivo y comprensivo aplicado en este análisis de la vida de Hilario Ramírez Morales conjuga interpretación y comprensión de textos y contextos reales que, como plantea Tatiana Fonseca (2008, p. 167), incluyen las intencionalidades narrativas de los autores cuando escriben los resultados de una investigación social. De ahí la importancia de ir paulatinamente acercándose al objeto de estudio hermenéutico, definiendo los términos claves como elementos del "primer modelo mental" en el nivel de la realidad cotidiana estudiada y en el lenguaje de esta (Tena y Rivas, 2007, p. 20). La perspectiva descrita sitúa la posibilidad invaluable de profundizar un estudio de mayor dimensión de la vida y acciones del personaje Hilario Ramírez, y articular, además, la hermenéutica histórico-crítica y la etnografía activa de orden antropológica para hacer lecturas densas y vivencias a profundidad que recuperen los propios lenguajes directos de los actores por los investigadores.

\section{Futuras Líneas de Investigación}

El área mixteca (na savi) que se describe en este estudio encierra una veta de investigación potencialmente apta para profundizar en las ciencias en general, y de forma particular en las sociales, con énfasis en la parte cultural y antropológica. A nuestro juicio es factible desarrollar líneas de investigación de interés para profesionales y estudiosos, así como para tesistas de dichas áreas, a fin de que se abunde en el conocimiento de las grandes problemáticas que aquejan al pueblo mixteco del Municipio de Ayutla o de otros territorios aledaños, cuyas condiciones de vida son similares, incluso que pueden ser peores.

En el sentido señalado, dada nuestra vocación por la antropología social y el compromiso adquirido en esta zona de indagación consideramos que se requiere mayor profundidad y trabajos complementarios, donde se pueda dar cuenta de la historia étnica del "pueblo de la lluvia"e na savi ("la gente de la lluvia").

En un contexto más amplio como es la Mixteca de la Región Costa Chica de Guerrero, proponemos “complementar" este trabajo, con temas de investigación como: 
Revista Iberoamericana

de las Ciencias Sociales y

Humanísticas

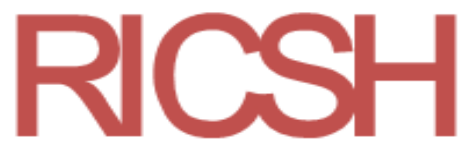

ISSN: $2395-7972$

1. Trascedencia social y política del Sistema Autónomo de Gobierno Municipal en Ayutla de los Libres

2. Avances y retrocesos del ejercicio del sistemas de usos y costumbres en comunidades mixtecas del Municipio de Ayutla de los Libres.

3. Estructura organizativa y funcionamiento, de las autodefensas comunitarias (Policía Comunitaria) en la zona mixteca de Ayutla de los Libres, así como su impacto para la seguridad social, económica, política y cultural de los ciudadanos frente a la delincuencia organizada y otros actores en el Municipio.

4. Violencia, racismo y discrimación hacia los pueblos indígenas y afromestizos de la Costa Chica del estado.

5. Memoria y oralidad entre los pueblos afromestizos de la Costa Chica de Guerrero. 


\section{Revista Iberoamericana \\ de las Ciencias Sociales y \\ Humanísticas}

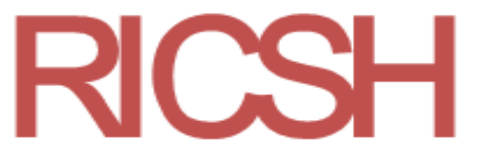

ISSN: $2395-7972$

\section{Referencias}

Dehouve, D. (2001). Cuando los banqueros eran santos. México: Ediciones Universidad Autónoma de Guerrero.

Fernández, M. Á. (2013). Los Sentimientos de la Nación de José María Morelos. Antología documental. México: Instituto Nacional de Estudios Históricos de las Revoluciones de México-Secretaría de Educación Pública.

Fonseca, T. (2008). Comprensión crítica de concepciones tradicionales del desarrollo desde trabajo el social: investigación documental. Tendencias \& Retos, (13), 165-184. Recuperado de http://www.ts.ucr.ac.cr/binarios/revistas/co/rev-co-tendencias-001311.pdf.

García, J. (20 de enero de 2011). Guillermo Sánchez Nava. La Jornada Guerrero, p. 3.

García, J. (21 de enero de 2011). Guillermo Sánchez Nava. La Jornada Guerrero, p. 3

García, J. (2012). Ñuu Savi: entre la resistencia y la continuidad histórica. Ponencia presentada en el Segundo Congreso Ñu Savi. Guerrero, del 10 al 12 de octubre de 2012. Recuperado de https://tuunsavi.weebly.com/uploads/2/5/7/3/25733861/ponencia_jaime_garca_leyv a.pdf

González, E. M. (2013). Acerca del estado de la cuestión o sobre un pasado reciente en la investigación cualitativa con enfoque hermenéutico. Uni-Pluri/Versidad, 13(1), 1-4. Recuperado

de http://bibliotecadigital.udea.edu.co/bitstream/10495/3313/1/GonzalesElvia_2013_es tadocuestioninvestigacioncualitativa.pdf

Gunder, A. (1967). Capitalismo y subdesarrollo en América Latina. México: Siglo XXI Editores. Recuperado de http://www.archivochile.cl/Ideas_Autores/gunderfa/gunderfa0006.pdf.

Hernández, L. (24 de febrero de 2009). Raúl Lucas: siembra de odio, cosecha de ira. La Jornada. Recuperado de http://www.jornada.unam.mx/2009/02/24/opinion/017a1pol

López, F. (2015). El fuego y las cenizas: los pueblos mixtecos en la guerra de Independencia. Oaxaca, México: Edición Coapi-Pez en el Árbol.

Luna, R. (2004). Geodemografía del Municipio de Ayutla de los Libres. Ayutla, México: Ediciones del H. Ayuntamiento Municipal. 


\section{Revista Iberoamericana \\ de las Ciencias Sociales y \\ Humanísticas}

ISSN: $2395-7972$

Narciso, B. (2002). Monografía y glosario mixteco. Guerrero, México: Ediciones H. Ayuntamiento de Ayutla de los Libres.

Pérez, J. J., Nieto, J. A. y Santamaría, J. E. (2019). La hermenéutica y la fenomenología en la investigación en ciencias humanas y sociales”. Civilizar: Ciencias Sociales y Humanas, 19(37), 21-30. Recuperado de https://revistas.usergioarboleda.edu.co/index.php/ccsh/article/view/V19n37a09/119 3

Rubí, R. (1993). Comunidades indígenas, siglos XVI y XVII del centro y la montaña de Guerrero. Estudios de Cultura Náhuatl, (23), 297-341.

Soriano, S. (1994). Lucha y resistencia indígena en el México colonial. México: Centro de Investigaciones Humanísticas de Mesoamérica y el Estado de Chiapas.

Tapia, J. (2015). Breve historia de la Auténtica Casa del Estudiante Guerrerense. Chilpancingo, México: Ediciones Universidad Autónoma de Guerrero.

Tapia, J. (2018). Cultura y resistencia de los mixtecos (Na Savi) del municipio de Ayutla de los Libres, Guerrero. (Tesis doctoral inédita). El Colegio de Morelos, Cuernavaca.

Tena, A. y Rivas, R. (2007). Manual de investigación documental. Elaboración de tesinas. México: Ediciones Plaza y Valdés.

Vélez, R. (1998). Los mixtecas (Etnohistoria ¿1521?). En Jiménez, E., Martínez, G. y Arboleyda, A. (coords.), Historia general de Guerrero. Época prehispánica: Arqueología. Etnohistoria (vol. I) (pp. 234-255). México: Conaculta-INAHGobierno de Guerrero-JGH Editores.

Vidal, F. (1987). Los yopis en el estado de Guerrero. Chilpancingo, Guerrero: Instituto Guerrerense de la Cultura.

Widmer, R. (1990). Conquista y despertar de las costas de la mar del Sur (1521-1684). México: Consejo Nacional para la Cultura y las Artes.

Entrevistas a líderes mixtecos de Ayutla de los Libres, Guerrero:

- Narciso Morales, Benito. Ayutla, 1989, 1999, 2002 (JCTG)

- Francisco Santis, Filemón. Ayutla, 1982, 2016 (JCTG) 


\section{Revista Iberoamericana \\ de las Ciencias Sociales y \\ Humanísticas}

ISSN: $2395-7972$

\begin{tabular}{|c|c|}
\hline Rol de Contribución & Autor (es) \\
\hline Conceptualización & $\begin{array}{l}\text { José Carmen Tapia Gómez-Principal, Rosalba Díaz Vásquez- } \\
\text { Apoyo }\end{array}$ \\
\hline Metodología & $\begin{array}{l}\text { Rosalba Díaz Vásquez-Principal, José Carmen Tapia Gómez- } \\
\text { Apoyo }\end{array}$ \\
\hline Software & No aplica \\
\hline Validación & No aplica \\
\hline Análisis Formal & No aplica \\
\hline Investigación & $\begin{array}{l}\text { José Carmen Tapia Gómez-Principal, Rosalba Díaz Vásquez- } \\
\text { Apoyo }\end{array}$ \\
\hline Recursos & No aplica \\
\hline Curación de datos & No aplica \\
\hline $\begin{array}{l}\text { Escritura - Preparación del } \\
\text { borrador original }\end{array}$ & José Carmen Tapia Gómez \\
\hline $\begin{array}{l}\text { Escritura - Revisión y } \\
\text { edición }\end{array}$ & $\begin{array}{l}\text { Rosalba Díaz Vásquez-Principal, José Carmen Tapia Gómez - } \\
\text { Apoyo }\end{array}$ \\
\hline Visualización & Rosalba Díaz Vásquez \\
\hline Supervisión & Rosalba Díaz Vásquez \\
\hline Administración de Proyectos & José Carmen Tapia Gómez. \\
\hline Adquisición de fondos & José Carmen Tapia Gómez \\
\hline
\end{tabular}

